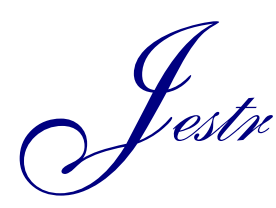

\title{
Anchorage Mechanical Characteristics of Newly Designed Rebar Bolt and Optimization of its Support Scheme
}

\author{
Bingjie Huo ${ }^{1}$, Xuedong Jin ${ }^{1}$ and Chen Cao ${ }^{1,2,3^{*}}$ \\ ${ }^{1}$ College of Mining, Liaoning Technical University, Fuxin 123000, China \\ ${ }^{2}$ International Joint Research Laboratory of Henan Province for Underground Space Development and Disaster Prevention, Henan \\ Polytechnic University, Jiaozuo 454003, China \\ ${ }^{3}$ CME, EIS, University of Wollongong, NSW 2522, Australia
}

Received 2 January 2019; Accepted 16 May 2019

\begin{abstract}
In Shendong coalfield, large cross-section underground gateways are often excavated for large machine transportation. It causes large deformation of the surrounding rock and the phenomenon of rib spalling. In this study, taking Xiaobaodang coal mine as the engineering background, a newly designed rebar bolt for large deformational roadway support was introduced to control large deformation. Results that the peak anchoring force of the new bolt increased by $20-30 \%$, the total energy absorption of the system is increased by $35-50 \%$, the post-peak displacement increases by $4.5 \mathrm{~mm}$ comparing with traditional left-spiral non-longitudinal rebar bolt. The support schemes were analyzed by using FLAC3D, the newly bolting effect was better than the original scheme when the new rebar bolt was used in full-length anchorage and the increased bolting interval. This study provides a referencr for the similar roadway support.
\end{abstract}

Keywords: Roadway, Large deformation, Support scheme, Rebar bolt, Numerical simulation

\section{Introduction}

Safety and efficient production of coal is an important aspect for the sustainable development of the economy. Rock bolting support technology has been widely used in underground coal mines for its advantages of strong adaptability to engineering geological conditions, high excavation rate, low labor intensity, high support strength and low support cost. It is the main support technology for underground roadway in coal mines worldwide [1-4].

In recent years, with the increase of mining intensity and the increase of mining equipment in underground coal mines, the number of high-rib and large-cross section underground roadways has gradually increased. Largecross-section roadway is also beneficial to ventilation, transportation and reserve space for surrounding rock deformation, which isconducive to installation of large equipment and safe production [5]. However, the increase of roadway crosssection has a significant impact on the stability of the tunnel ribs, the large deformation of the coal ribs affects the stability of the whole roadway, which brings great difficulties on roadway support [6].

Large deformation roadway support has been studied in literature. Zhang et al. suggestedthat the traditional I-beam support cannot meet the large deformation of surrounding rock caused by large cross-section mining roadway under fully mechanized top coal caving mining method. Through an industrial test, a staggered support method for large cross-

*E-mail address: 2065214306@qq.com

ISSN: $1791-2377$ @ 2019 Eastern Macedonia and Thrace Institute of Technology. All rights reserved. doi:10.25103/jestr.122.13 section roadway is developed [7]. Meng et al. have studied the large cross-section roadway developed in weak and fractured surrounding rock, and developed full cross-section bolt-mesh and shotcrete primary support, high-prestressing cable bolt and cement grouting secondary reinforcement support scheme. Through numerical simulation, similarity material experiment and industrial experiment, it is proved that the scheme can effectively control the large deformation and floor heave of large cross-section roadway excavated in weak and fractured surrounding rock [8]. Liu et al. studied the floor heave of large cross-section mining roadway, and considered that the floor heave increased linearly with the increase of roadway width. It was proposed that the floor heave could be better prevented by strengthening the corner of the roadway and installing the floor bolt [9].

At present, the conventional rebar bolt is often used as support material, or the high-strength bolt or yieldable bolt is introduced to cooperate with secondary support to improve the safety, however, these measures often increase the installation difficulty, technical difficulty and construction cost, and often reduces the development rate due to the increase of support density [10-14]. Therefore, increasing the surrounding rock controlling ability of the primary support by improving the rebar bolting capability without increasing the support cost, is of great practical significance for rebar bolt support in the large cross-section mining roadway.

Based on the engineering background of rockbolting of large cross-section mining roadway in Xiaobaodang Coal Mine, the authorsdevelop a new type of fully grouted rock bolt without increasing development cost. Through laboratory and field tests, the bolting performance of leftscrew steel bolt and the new bolt are compared. The supporting effect of two bolts is numerically studied using 
FLAC3D software. Finally, the support design for Xiaobaodang mining roadway was optimized, which provides a reference for similar large cross-section coal mine roadway support design.

The rest of this study is organized as follows. Section 2 gives the design of the rebar bolt. Section 3 presents the laboratory pullout tests and its results. Section 4 describes the experimental studies in the field, Section 5 conducts the optimization analysis of the support schemes by using FLAC3D and finally, the conclusions are summarized in Section 6.

\section{Rebar bolt design}

The rebar bolt profile has great influence on the bolting performance. Based on the previous research results of bolt profile optimisation, this paper proposes a trapezoidal large rib spacing left spiral bolt, namely $\mathrm{C} 1$ bolt, as shown in Fig. 1.
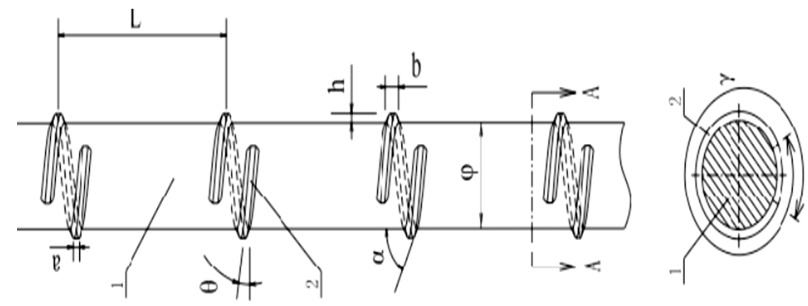

Fig. 1. Design of the new bolt (C1 bolt)

The diameter of the proposedrebar bolt in this paper is $20 \mathrm{~mm}$, the transverse rib spacing is of $50 \mathrm{~mm}$, the rib height is $2 \mathrm{~mm}$. The cross-section of the transverse rib is trapezoidal, with top width $1.5 \mathrm{~mm}$ and bottom width 3.6 $\mathrm{mm}$. The helix angle of the transverse rib is of $80^{\circ}$, and the one transverse rib spirals $405^{\circ}$ around the anchor body. The overlaid spiral section is of $45^{\circ}$ designed for resin flowing during the anchoring installation. The profile parameter of $\mathrm{C} 1$ bolt is shown in Table 1. C2 bolt is left-handed nonlongitudinal rebar bolt commonly used in underground coal mine industry in China. The profile parameters of $\mathrm{C} 2$ bolt is also shown in Table 1.

Table 1. Geometric parameters of two kinds of bolts

\begin{tabular}{c|c|c|c|c}
\hline \multicolumn{2}{c|}{ Rebar Bolt } & $\begin{array}{c}\text { Diameter } \\
(\mathbf{m m})\end{array}$ & $\begin{array}{c}\text { Rib } \\
\text { spacing } \\
\text { (mm) }\end{array}$ & $\begin{array}{c}\text { Rib height } \\
(\mathbf{m m})\end{array}$ \\
\hline $\mathrm{C} 1$ & & 21 & 13 & 1.2 \\
$\mathrm{C} 2$ & & 20 & 50 & 1.8 \\
\hline
\end{tabular}

\section{Laboratory pullout tests}

\subsection{Pullout test of steel sleeve}

In laboratory pullout tests, steel sleeve was selected as confining material. The length of the tube is $100 \mathrm{~mm}$; its inner diameter is $30 \mathrm{~mm}$ and wall thickness is $5.5 \mathrm{~mm}$, respectively. To prevent slip at resin-sleeve interface, the sleeve was threaded with thread pitch of $1.0 \mathrm{~mm}$. Two kinds of the rebar bolts were cut into $280 \mathrm{~mm}$ length and anchored into the steel sleeve using resin grout. The average uniaxial compressive strength and shear strength of the resin are measured as $60.9 \mathrm{MPa}$ and19.5 $\mathrm{MPa}$, respectively. The measured Young's modulus is 12.6 GPa and Poisson's ratio is of 0.26 .In the preparation, efforts had been made to ensure the bolt to be centered and parallel to the sleeve axis, so that the resin thickness is uniform, as shown in Fig. 2.

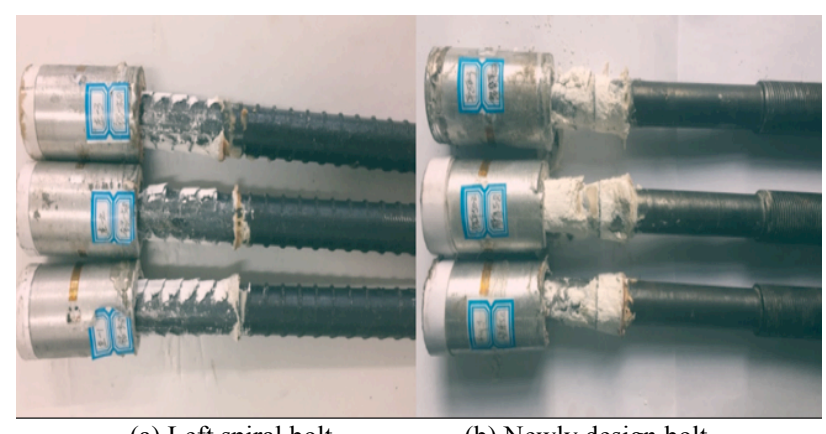

(a) Left spiral bolt

Fig. 2. Test bolting samples

(b) Newly design bolt

WAW-600C electro-hydraulic servo universal testing machine controlled by microcomputer with a maximum test force of $600 \mathrm{kN}$ was used, as shown in Fig. 3. The prepared specimens are placed in a frame and clipped by the testing machine, and the testing was displacement control with loading rate of $1.0 \mathrm{~mm} / \mathrm{min}$.

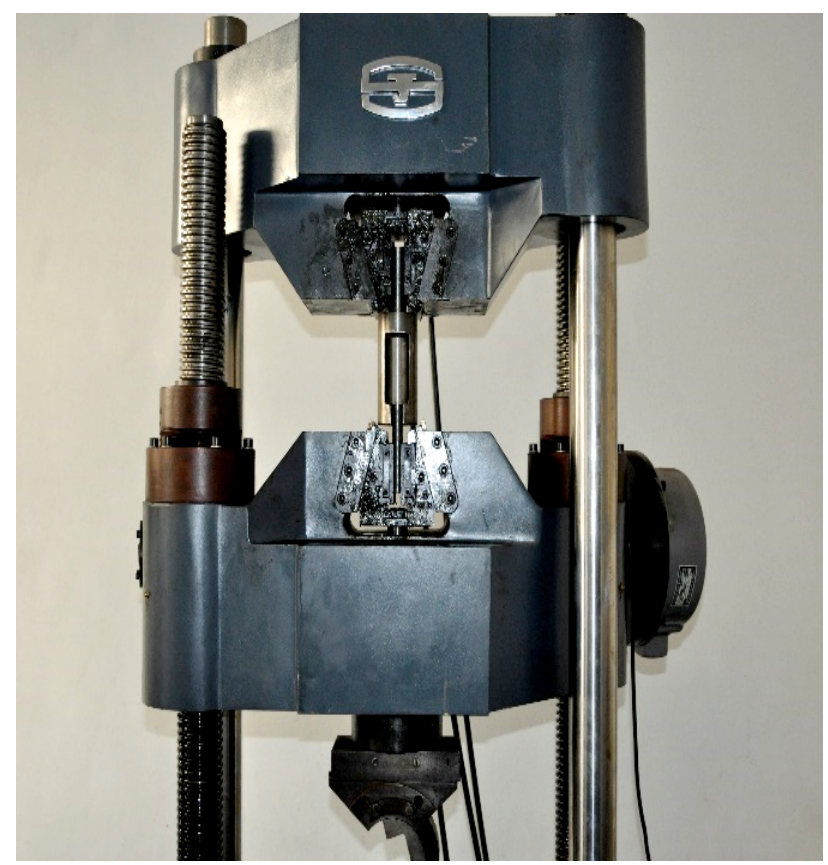

Fig. 3. Testing machine

The pullout curve is shown in Fig. 4. It can be seen that the average peak load of commonly used rebar bolt is 106.2 $\mathrm{kN}$; and the average peak axial load of the newly design rebar bolt is $128.1 \mathrm{kN}$, which is $20.6 \%$ higher than former's. From a viewpoint of energy absorption (area under the pullout curve), the average energy absorption of $\mathrm{C} 1$ and $\mathrm{C} 2$ bolts are $2.90 \mathrm{~kJ}$ and $4.46 \mathrm{~kJ}$, respectively.

Fig. 5 shows the displacements of the two kinds of anchors while the pulling force is greater than $90 \mathrm{kN}$. The average axial displacement of the new bolts with a pulling force of $90 \mathrm{kN}$ or higher is $25.9 \mathrm{~mm}$, and the axial displacement of the left spiral rebar bolts is $4.6 \mathrm{~mm}$. The peak pulling force of the new anchor reaches to a displacement of about $26 \mathrm{~mm}$, and the peak pulling force of the left spiral rebar bolt corresponds to a displacement of about $6 \mathrm{~mm}$, which indicates an offset displacement up to 20 $\mathrm{mm}$. 


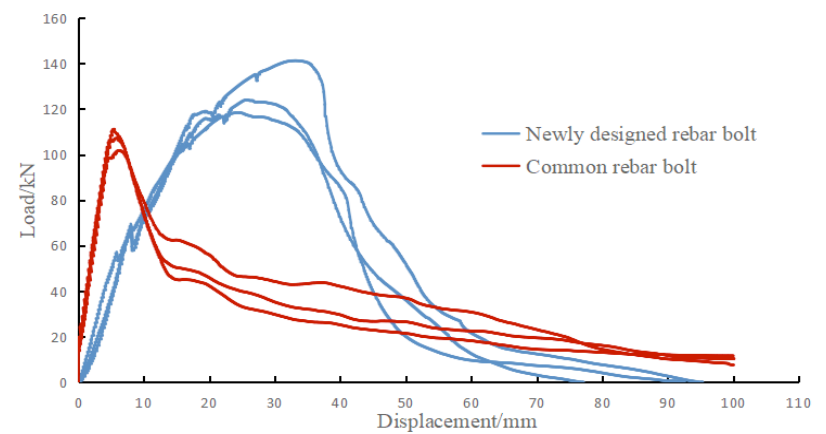

Fig. 4. Load-displacement curves of two kinds of anchor sleeves

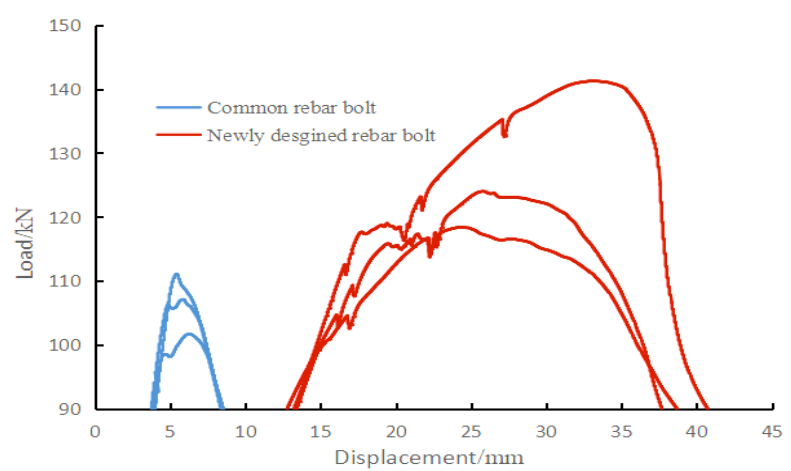

Fig. 5. Pulling force and displacement when drawing force is greater than $90 \mathrm{kN}$

It can be seen that the $\mathrm{C} 1$ anchor reaches its peak pulling force when the bolt deformation is about $6 \mathrm{~mm}$, and the axial displacement is only $4.6 \mathrm{~mm}$ for anchor resistance greater than $90 \mathrm{kN}$. The new anchor reaches peak pulling force at bolt deformation of $26 \mathrm{~mm}$ with a axial displacement of 25.9 $\mathrm{mm}$. Compared with the left spiral bolt, the anchorage performance of the new bolt is preferred for large deformation of the surrounding rock.

\subsection{Pullout test of concrete block}

The height of the roadway is $4.2 \mathrm{~m}$, roof pull-out test does not carry out for safety reason. In the laboratory, a cubic 1 $\mathrm{m}^{3}$ concrete pier made of fine sand and cement is used to simulate the roof sandstone conditions. Pullout test was carried out using the concrete block, as shown in Fig. 6.

The result of concrete pullout is shown in Fig. 7. The average peak load of the $\mathrm{C} 1$ bolt $(114.9 \mathrm{kN})$ is $21.6 \%$ higher than that of $\mathrm{C} 2$ bolt $(94.24 \mathrm{kN})$. The axial displacement at the peak load of $\mathrm{C} 1$ bolt is $12.6 \mathrm{~mm}$, is $8.6 \mathrm{~mm}$ for $\mathrm{C} 2$ bolt.It indicates a shift of $4.5 \mathrm{~mm}$. The average total energy absorption of the $\mathrm{C} 1$ bolting specimen $(5321 \mathrm{~J})$ is $36.2 \%$ higher than that of C2 (4275 J).

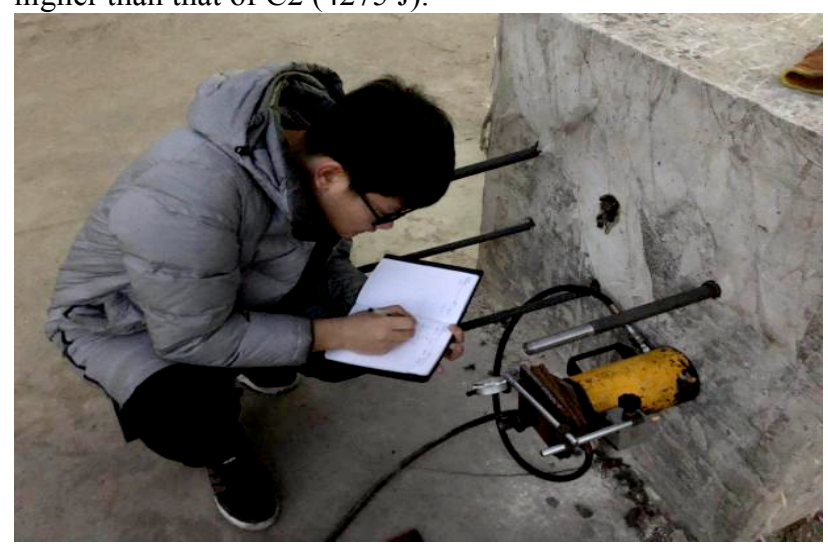

Fig. 6. Pullout test using concrete block.

\section{Field pullout test}

Considering the reliability of field application of the experimental data, field pullout experiments were carried out at $630 \mathrm{~m}$ and $2430 \mathrm{~m}$ of the roadway of 112201 longwall panel of Xiaobaodang Coal Mine. The anchoragelength is $150 \mathrm{~mm}$, and the grouting agent is MSK2335 resin grout. Entangle with Tape was used to entangle the bolt at $150 \mathrm{~mm}$ end of bolt to avoid overflow of anchoring agent, as shown in Fig. 8.

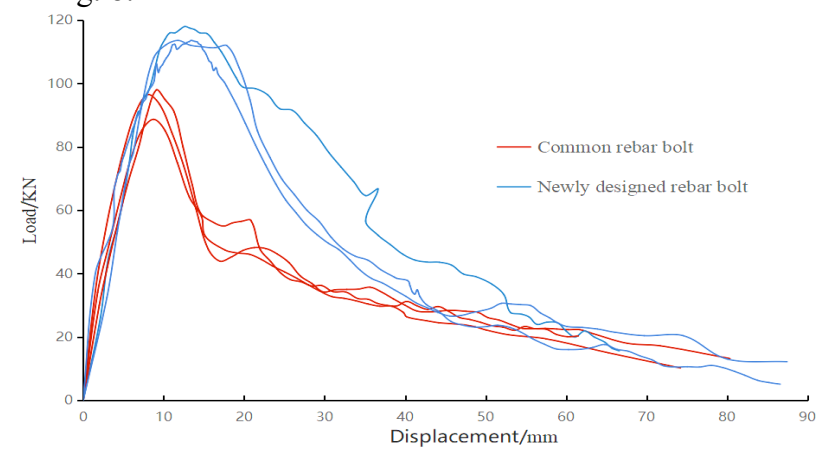

Fig. 7. Pullout curves of concrete block

The result of rib pullout is shown in Fig. 9. The average peak pull-out load of new bolt is $99.2 \mathrm{kN}$, the average peakpull-out load of commonly used left spiral bolt is 73.9 $\mathrm{kN}$, and the peak load displacement of $\mathrm{C} 1$ bolt is $12.2 \mathrm{~mm}$, C2 bolt is $7.7 \mathrm{~mm}$, offset is $4.5 \mathrm{~mm}$.

The area under the pullout curve is the total energy absorbed by the anchorage system, that is, the required energy for the failure of the anchorage.It is an important index of the anchorage effect. The higher the requiredtotal energy, the better the anchorage performance. At present, there are several kinds of specially designed bolt to improve the total energy absorption [15-17]. The average total energy absorption of $\mathrm{C} 1$ system is $4901 \mathrm{~J}$, and that of $\mathrm{C} 2$ system is $3267 \mathrm{~J}$. The average total energy absorption of $\mathrm{C} 1$ system is $50 \%$ higher than that of $\mathrm{C} 2$ system.

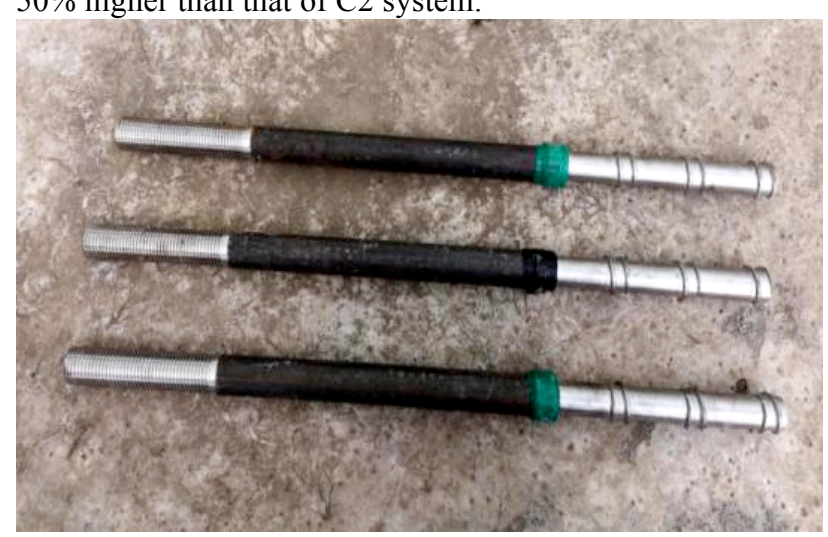

Fig. 8. C1 bolt used for field test

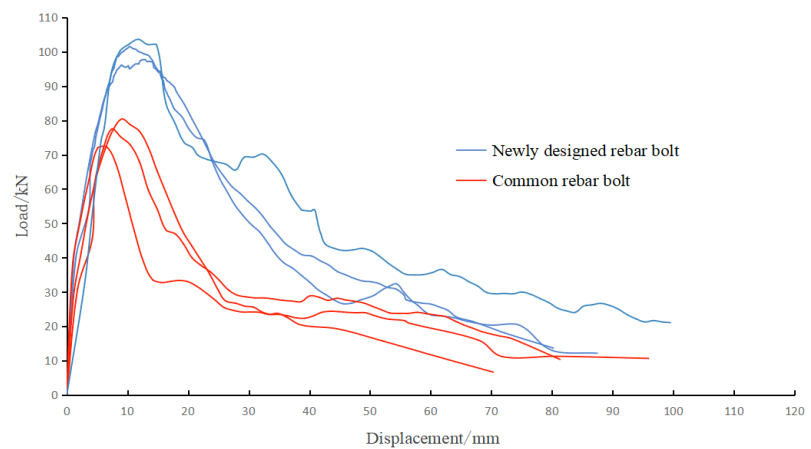

Fig. 9. Pullout curves from the roadway rib 
The peak pull-out force and energy absorption of the bolt control the bolting effect of surrounding rock. The average peak pullout force of the new bolt is $20-30 \%$ higher than that of the commonly used rebar bolt; thedisplacementat peak load is $4.5 \mathrm{~mm}$ larger, and the total energy absorption of the system increases by $35-50 \%$ on average. It shows that the new bolt maintains a high strength in the case of large deformation, and can be used for large deformation of surrounding rock.

\section{Numerical study of support design}

\subsection{Support design}

The original support scheme of Xiaobaodang large crosssection roadway is, the roof and the pillar rib adopt ordinary rebar bolts with $\phi 20 \mathrm{~mm} \times 2400 \mathrm{~mm}$, the spacing of roof bolt is $850 \mathrm{~mm} \times 900 \mathrm{~mm}, 7$ per row; spacing in the pillar rib is of $900 \mathrm{~mm} \times 900 \mathrm{~mm}, 5$ in a row, and the anchoring length is $1300 \mathrm{~mm}$. Pre-tightening torque of the bolts is 60 $\mathrm{N} \cdot \mathrm{m}$ in pillar rib, roof bolt pre-tightening torque is $120 \mathrm{~N} \cdot \mathrm{m}$. Roof cable specification is $17.8 \mathrm{~mm} \times 6300 \mathrm{~mm}$, anchorage length $1700 \mathrm{~mm}$. The cable is arranged between the two rows of rebar bolt anchors. The panel ribadopts $\phi 22 \mathrm{~mm} \times$ $2400 \mathrm{~mm}$ glass fiber reinforced polymer (FRP) bolt to prevent the shearer from rubbing with the steel anchor during the mining process to ensure the safe production of the mine. The spacing at the panel rib is $900 \mathrm{~mm} \times 900 \mathrm{~mm}$.

An optimization scheme has been developed, roof bolt and pillar bolt are replaced by the new rebar bolt. Original $\phi 22 \mathrm{~mm}$ FRP anchors are replaced by $\phi 27 \mathrm{~mm}$ FRP bolt. The spacing becomes $900 \mathrm{~mm} \times 1000 \mathrm{~mm}$, the anchoring method is changed from the end anchoring to the full-length anchoring.The pre-tightening torque of the roof and the pillar rib bolts are $150 \mathrm{~N} \cdot \mathrm{m}$, and the anchor cable support scheme is unchanged.

\subsection{Numerical simulation}

The deformation of the roadway is studied under the existing support scheme of the mining roadway, the full-length anchoring of the existing supporting scheme, and the fulllength anchoring of the new bolt scheme by using FLAC3D. Tables 2 and 3 show the physical and mechanical parameters of the coal and rock and mechanical parameters of anchors.

Table. 2. Mechanics parameters of coal and rock

\begin{tabular}{c|c|c|c|c|c|c}
\hline Lithology & $\begin{array}{c}\text { Bulk Weight } \\
\left(\mathrm{g} / \mathrm{cm}^{3}\right)\end{array}$ & $\begin{array}{c}\text { Tensile strength } \\
(\mathbf{M P a})\end{array}$ & $\begin{array}{c}\text { Cohesion strength } \\
(\mathbf{M P a})\end{array}$ & $\begin{array}{c}\text { Friction } \\
\text { angle } \boldsymbol{\varphi} \\
\left({ }^{\circ}\right)\end{array}$ & $\begin{array}{c}\text { Elastic Modulus } \\
(\mathbf{M P a})\end{array}$ & $\begin{array}{c}\text { Poisson's ratio } \\
\mathbf{v}\end{array}$ \\
\hline Siltstone & 2.37 & 1.03 & 5.82 & 37 & $1.95 \mathrm{E} 4$ \\
Sandy mudstone & 2.36 & 1.44 & 5.12 & 35 & $2.7 \mathrm{E} 4$ \\
Medium sandstone & 2.30 & 1.32 & 6.09 & 32 & 0.21 \\
Fine sandstone & 2.33 & 1.59 & 9.42 & 34 & $2.4 \mathrm{E} 4$ \\
Coal seam & 1.33 & 0.44 & 4.40 & 0.19 & 34 & 0.18 \\
\hline
\end{tabular}

Table. 3. Parameters of cable structural element

\begin{tabular}{c|c|c|c|c|c|c|c}
\hline Material & $\begin{array}{c}\text { Density } \\
\left(\mathrm{kg} / \mathrm{m}^{3}\right)\end{array}$ & $\begin{array}{c}\text { Elastic } \\
\text { Modulus (GPa) }\end{array}$ & $\begin{array}{c}\boldsymbol{k}_{\mathrm{g}} \\
(\mathbf{G N} \cdot \mathbf{m})\end{array}$ & $\begin{array}{c}\boldsymbol{c}_{\mathrm{g}} \\
\left(\mathrm{MN} \cdot \mathrm{m}^{2}\right)\end{array}$ & $\begin{array}{c}\text { Out perimeter } \\
(\mathbf{m})\end{array}$ & $\begin{array}{c}\text { Cross-sectional } \\
\text { area }\left(\mathrm{m}^{2}\right)\end{array}$ & $\begin{array}{c}\text { Maximum breaking } \\
\text { force }(\mathbf{k N})\end{array}$ \\
\hline Rebar bolt & 7900 & 201 & 14 & 0.895 & 0.069 & $3.14 \times 10^{-4}$ & \\
FRP & 2100 & 70 & 12 & 0.432 & 0.085 & $5.72 \times 10^{-4}$ \\
New rebar bolt & 7900 & 201 & 14 & 1.100 & 0.069 & $3.14 \times 10^{-4}$ & 280 \\
\hline
\end{tabular}

Through borehole peeping and physical and mechanical properties testing of rock samples, it is found that the roof is hardrock, there are no obvious cracks, and the roof condition is good. The simulation results show that although the roof subsidence has been reduced, it is not very obvious. The displacement nephogram of the roof subsidence is not given here.

Through the numerical calculation of the existing support scheme, the present support parameter full-length anchorage scheme and the new bolt scheme, it can be seen (Fig. 10) that the pillar rib deformation of the full-length anchorage of the original support parameter has been reduced from $188 \mathrm{~mm}$ to $165 \mathrm{~mm}$, with a reduction of $12 \%$. The deformation of the pillar rib the new bolt scheme is 143 $\mathrm{mm}$, with a reduction of $24 \%$. The simulation results are limited to anchoring force of the new bolt, but the advantages such as strong energy absorption and large displacement of peak load retention, are not reflected. It can be seen that the new type bolt has the advantage of controlling the large deformation of roadway.
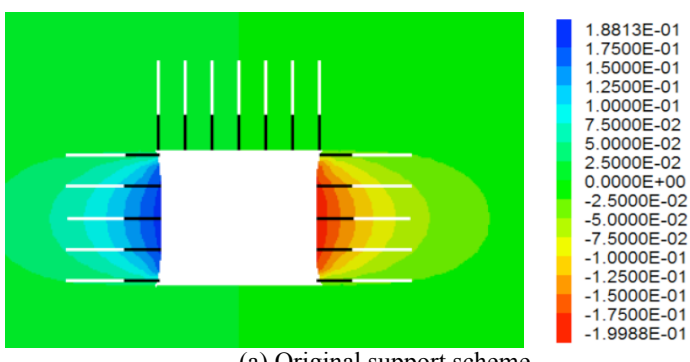

(a) Original support scheme

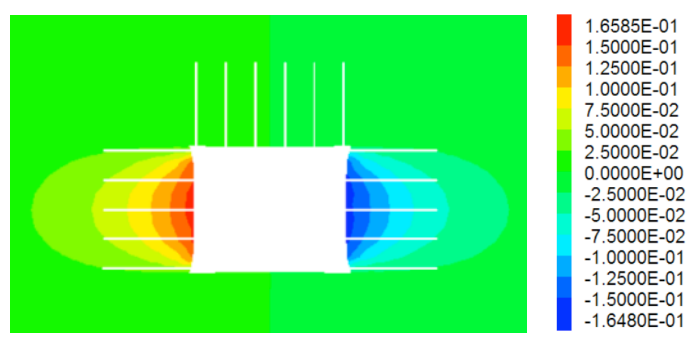

(b) Full length anchoring of original support parameters 


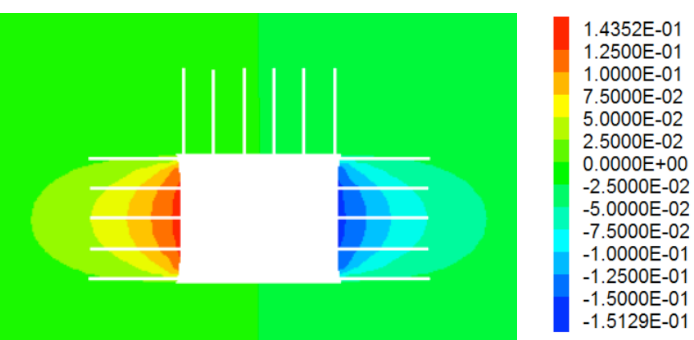

(c) New rebar bolt optimization solution

Fig. 10. Horizontal displacements fields of different schemes

\section{Conclusions}

To realize rock bolting optimization of large cross-section roadway support with respects to strata controlling and development economy, a newly designed rebar bolt was introduced to control large deformation, the laboratory and field pullout tests were conducted, the mainly conclusions are as follows:

(1) A new rebar bolthas been designed with diameter 20 $\mathrm{mm}$, the transverse rib spacing $50 \mathrm{~mm}$, the rib height $1.8 \mathrm{~mm}$. The transverse rib shape is trapezoidal, and the rib top width is $1.5 \mathrm{~mm}$ and the rib bottom width is $3.6 \mathrm{~mm}$. The transverse rib has a helix angle of $80^{\circ}$ on the outer surface of the rod, and the same transverse rib spirals $405^{\circ}$ around the anchor body.
(2) In terms of anchoring performance, in the laboratory test, the new anchor bolting force is increased by $20 \%$ on average, and the load peak displacement is shifted by up to $20 \mathrm{~mm}$. In field tests, the new rebar bolt has an average anchorage force of $20-30 \%$ higher than that of the common rebar bolt, the total energy absorption of the system is increased by $35-50 \%$, and the peak displacement of the load is greatly offset by $4.5 \mathrm{~mm}$.

(3) The new bolt full-length anchoring optimization scheme is effective than the original scheme support under the field condition.

Although the optimized design of this study has achieved good results in the practice, with the development of mining engineering, the advanced bolting support that meets the requirements of large deformation control and low cost needs to be further researched.

\section{Acknowledgements}

This work was financially supported by the National Natural Science Foundation of China (51774112).

This is an Open Access article distributed under the terms of the Creative Commons Attribution License

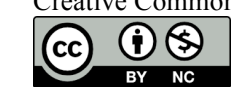

\section{References}

1. Yu, B., "High-strength bolt support technology and its application in large cross-section coal roadway". Coal Science and Technology, 39(8), 2011, pp. 5-8.

2. Wang, S. R., Xiao, H. G., Cao, C., Zou, Z. S., Liu, X. L., "Simulation verification analysis of anchoring characteristics of transverse rib steel bar during pull-out test". DYNA, 91(5), 2016, pp. 548-553.

3. Wang, S. R., Xiao, H. G., Hagan, P., Zou, Z. S., "Mechanical behavior of fully-grouted bolt in jointed rocks subjected to double shear tests". DYNA, 92(3), 2017, pp. 314-320.

4. Han, J., Wang, S. R., Chen, Y., Cao, C., "Analytical derivation of rib bearing angle of reinforcing bar subject to axial loading”. Magazine of concrete research, 71(4), 2019, pp. 175-183.

5. Zhang, W., Zhang, D. S., Wang, X. F., Wu, X., "Effect analysis of bolt-beam-mesh-cable combined support in large cross-section mining roadway". Coal Engineering, (7), 2008, pp. 64-66.

6. Xu, B. G., "Experimental study on bolt support for primary roadway formation in fully mechanized excavation of large cross-section roadway”. Journal of Mining and Safety Engineering, (3), 2006, pp. 370-373.

7. Zhang, C. Z., Song, G. D., Ling, J. B., Zhang, G. Q., Zhang, Y. S., Yang, R. S., "Experimental study on bolt support of large crosssection mining roadway in whole coal seam". Coal Engineering, (6), 1994, pp. 4-7.

8. Meng, Q. B., Han, L. J., Qiao, W. G., Zong, Y. J., Li, Y., Li, H., "Evolution law and control technology of coal roadway with large cross-section weak and fractured surrounding rock". Journal of Coal Science, 41(8), 2016, pp. 1885-1895.

9. Liu, C., Song, E., Liu, Y., Zhang, X. L., Luo, W., "Mechanisms of floor heave in large cross-section mining roadway and its prevention and control countermeasures". Journal of Coal Science, 39(6), 2014, pp. 1049-1055.
10. Liu J. R., Kang, Q. T., "Surrounding rock control optimization design of large section soft seam roadway". Journal of Mining and Safety Engineering, 30(6), 2013, pp. 836-840

11. Wei, W. B., "Research and application of bolt-mesh-cable support technology for large section roadway". Master thesis of Inner Mongolia University of Science and Technology, , China, 2015, pp. 21-43.

12. Ren, B. X., Feng, C. H., Sun, R., Du, W. Z., "Research on coal roadway support technology based on FLAC3D". Coal Technology, 35(6), 2016, pp. 55-57.

13. Li, X. J., "Numerical simulation and support technology for strata behavior law of large cross-section mining roadway". Coal Science and Technology, 45 (S1), 2017, pp. 51-54.

14. Meng, Y., Bai, J. W., Zhang, X. G., "Study on Numerical Simulation of support optimization of large section limestone roadway". Journal of Shandong University of Science and Technology (Natural Science Edition), 31(5), 2012, pp. 21-25.

15. Li, C. C., "A new energy-absorbing bolt for rock support in high stress rock masses". International Journal of Rock Mechanics and Mining Sciences, 47(3), 2010, pp. 396-404.

16. Cai, M., Champaigne, D., "Influence of bolt-grout bonding on MCB conebolt performance". International Journal of Rock Mechanics and Mining Sciences, 49, 2012, pp. 165-175.

17. He, M. C., Gong, W. L., Wang, J., Qi, P., Tao, Z. G., Du, S., Peng, Y. Y., "Development of a novel energy-absorbing bolt with extraordinarily large elongation and constant resistance". International Journal of Rock Mechanics and Mining Sciences, 67, 2014, pp. 29-42. 